\title{
Produção de lágrima após exérese parcial da glândula lacrimal principal em cães
}

\author{
Tear production after partial removal of main lacrimal gland in dogs
}

\begin{abstract}
Camila Araújo Busnardo', Duvaldo Eurides', Letícia Binda Baungarten', Luiz Antônio Franco da Silva², Marcelo Emílio Beletti ${ }^{3}$, Ednaldo Carvalho Guimarães ${ }^{4}$, Lorena Borges Alves', Benito Juarez Nunes Alves de Oliveira ${ }^{1}$, Luis Augusto de Souza ${ }^{1}$, Andrigo Barbosa de Nadri ${ }^{5}$ \& Gentil Ferreira Gonçalves ${ }^{6}$
\end{abstract}

\begin{abstract}
Background: The partial loss of the lacrimal gland by obstruction, injury, removal of tumor tissue or other pathological changes may lead to loss of tear flow, bringing harmful consequences to the body. The aim was to evaluate the production of tears after removal of approximately $50 \%$ of the main lacrimal gland.

Materials, Methods \& Results: For this, lacrimal glands from the left eyes of seven dogs, male, adult, with weight ranging from 6 to $13 \mathrm{~kg}$ were partially removed. In each animal, an incision of approximately $3.0 \mathrm{~cm}$ of skin, orbicularis and cutaneous muscle of the eye between the eyeball and the zygomatic process of frontal bone of the lateral left side was performed. After incision of the conjunctiva, close to the zygomatic process, the orbital ligament was located and partially sectioned to expose the main lacrimal gland. With a stainless steel wire graph, the gland was measured and retired approximately 50\% of the parenchyma. The fragment was placed in a bottle containing $10 \%$ formalin for histological evaluation. The tears production was measured with lacrimal Schirmer test at $28^{\circ} \mathrm{C}$ and $70 \%$ relative humidity 24 hours before surgery and on the 15th, 30th and 60th days after surgery. At the 60th day, samples of gland lacrimal of the same animals were colleted for histopathologic examination of number, mean diameter of the acini and their nuclei, nucleus: cytoplasm ratio and cell area in a sample of 30 acini per animal and the density of collagen fibers. In the evaluations of the tears production with the Schirmer Test, between the pre-operative (PE), 15, 30 and 60 days post-operatively $(\mathrm{PO})$ were noticed significant differences $(\mathrm{p}=0.0033)$ at times between PE and 15 days of $\mathrm{PO}$ and between 15 and 60 days of PO. By comparing histological evaluation of lacrimal gland samples in the PE and after 60 days, there were significant differences in the lacrimal gland of nuclear area $(p>0)$, nuclear cytoplasm proportion $(\mathrm{p}=0.0006)$ and cell area $(\mathrm{p}=0.0083)$. The collagen fibers formation did not differ significantly between the PE and 60 days after partial removal of the gland $(\mathrm{p}=0.7104)$. All the ethical principles of ethical use of animals in experiments recommended by the Brazilian College of Animal Experimentation and Ethics Committee of the use of animals at the Federal University of Uberlandia.

Discussion: The partial removal allowed the lacrimal gland remaining to offset the production of aqueous tear film: the values found in tear production were above normal throughout the trial period. Induction of cells secreting tears to hyperactivity occurred to offset the demand of production after removing part of the gland. Thus, it was stimulated increase nuclear - giant and multiple nuclei in constant transcription-protein synthesis - and small cytoplasm with little storage tear. This fact explains the increase in cell at 60 days, the decrease in tear production after 24 hours and its return to normal parameters at 60 days postoperatively. In this experiment, the density of collagen fibers found throughout the parenchyma tear between the PE and after 60 days postoperatively was not significant, possibly due to the deposition of fibers are directed to the incision site and the inflammatory reaction, along with the deposition collagen fibers was terminated with 60 days postoperatively. Therefore, the partial removal of the main tear gland in dogs does not interfere significantly in the fall of tear production on day 60 of evaluation in which the tears production came back within the normal patterns.
\end{abstract}

Keywords: lacrimal gland, dog, tear, surgery.

Descritores: cão, glândula lacrimal, lágrima, cirurgia. 


\section{INTRODUÇÃO}

A glândula lacrimal é um tecido multi-lobular composto de células acinares, ductais e mioepiteliais e é o principal contribuinte para a camada aquosa do filme lacrimal. Os ácinos contêm $80 \%$ das células presentes na glândula lacrimal, onde se realiza a síntese, armazenagem e secreção de proteínas. Além disso, secretam eletrólitos e água, que participam da nutrição e proteção da superfície ocular [14].

A glândula principal se encontra dorsolateral ao bulbo do olho e seu tamanho é relativo ao do animal [5]. A unidade funcional lacrimal é composta pela glândula principal e acessória, superfície ocular e inervação interconectiva [13]. As secreções da glândula lacrimal são reguladas pelo sistema nervoso simpático, parassimpático e sensorial, sendo mais de um gânglio parassimpático envolvido na regulação neural da secreção da glândula lacrimal [2].

A lágrima e seus constituintes anti-inflamatórios reparam e previnem danos durante exposição da superfície ocular num indivíduo normal frente ao estresse ambiental ou exposição da superfície a bactérias e vírus [11]. A perda de alguma porção da glândula lacrimal pode acarretar prejuízo do fluxo lacrimal, com consequências danosas ao organismo. Nas patologias severas, como doenças autoimunes e idade avançada, a glândula lacrimal pode tornar-se um alvo do sistema imune, mostrar sinais de inflamação e produzir a ceratoconjuntivite seca (KCS) [14]. A proptose do globo ocular, o trauma direto na glândula principal ou a denervação parassimpática também podem ocasionar a KCS [3].

Objetivou-se avaliar a produção de lágrima após exérese aproximada de $50 \%$ do parênquima lacrimal principal em cães com produção lacrimal dentro dos parâmetros normais.

\section{MATERIAIS E MÉTODOS}

Foram utilizados sete cães, machos, adultos com peso variando de 6 a $13 \mathrm{~kg}$, considerados aptos ao experimento após exames oftálmicos de rotina, clínico e hematológico. Foram alojados em canis individuais durante um período mínimo de 15 dias para adaptação do local, onde receberam alimentação à base de ração e água à vontade. A produção de lágrima foi mensurada nos olhos esquerdos dos animais com o teste lacrimal de Schimmer ${ }^{\mathrm{a}}$ em temperatura ambiental ajustada para $28^{\circ} \mathrm{C}$ e $70 \%$ de umidade relativa do ar, 24 horas antes da cirurgia.

Após jejum de 12 horas de alimentos sólidos e seis horas de água, realizou-se tricotomia na região da órbita da face lateral esquerda dos animais. Ato contínuo, os cães receberam enrofloxacina ${ }^{2}(10,0 \mathrm{mg} /$ $\mathrm{kg}$, IM), flunixin meglumine ${ }^{3}(1,1 \mathrm{mg} / \mathrm{kg}, \mathrm{IM}) \mathrm{e}$ cloridrato de tramadol ${ }^{4}(2,0 \mathrm{mg} / \mathrm{kg}, \mathrm{IM})$. Após 30 minutos, foram submetidos a protocolo anestésico com acepromazina ${ }^{5}(0,1 \mathrm{mg} / \mathrm{kg}, \mathrm{IM})$, associação de cetamina $^{6}(5,0 \mathrm{mg} / \mathrm{kg}, \mathrm{IM})$ e xilazina ${ }^{7}(1,0 \mathrm{mg} / \mathrm{kg}, \mathrm{IM})$ e antissepsia do campo operatório com polivinilpirrolidona $^{8} 0,2 \%$.

Em cada animal, realizou-se uma incisão de aproximadamente $3,0 \mathrm{~cm}$ de pele, músculo cutâneo e orbicular do olho, entre o globo ocular e o processo zigomático do osso frontal da face lateral esquerda. Após incisão da conjuntiva, próximo ao processo zigomático, o ligamento orbitário foi localizado e parcialmente seccionado a fim de expor a glândula lacrimal principal (Figura 1-A). Com um fio de aço inoxidável milimetrado, a glândula foi mensurada e retirou-se aproximadamente $50 \%$ do seu parênquima (Figura 1-B). O fragmento foi acondicionado em frasco contendo formol $10 \%$ para avaliação histológica. O músculo orbicular e cutâneo foi aproximado com pontos em "X" e fio categute 3-0 cromado e a pele com pontos Wolf e fio náilon 4-0.

No pós-operatório (PO), as feridas de pele foram higienizadas com polivinil-pirrolidona a $0,2 \%$ e os pontos retirados ao $10^{\circ}$ dia de PO. Os animais receberam enrofloxacina $(5,0 \mathrm{mg} / \mathrm{kg}, \mathrm{SC})$ a cada 24 horas, por sete dias e flunixin meglumine $(1,1 \mathrm{mg} /$ $\mathrm{kg}, \mathrm{SC}$ ) a cada 24 horas, por três dias. A produção de lágrima foi mensurada através do Teste de Schimmer nos 15,30 e 60 dias de PO.

Foi feita comparação qualitativa da produção lacrimal utilizando o teste de Schirmer entre os momentos de pré-operatório (PE), 15, 30 e 60 dias de PO, por meio do teste de Qui-quadrado de Friedman com significância de $5 \%$.

Decorridos 60 dias de PO, os animais foram reoperados para coleta do restante da glândula lacrimal para avaliação histopatológica comparativa das amostras removidas no pré-operatório. Os fragmentos foram fixados em formol $10 \%$ por no mínimo 48 horas, incluídas em parafina e processados rotineiramente. As lâminas foram coradas pela técnica hema- 
toxilina-eosina (HE) e Picro-sírius-red. Os cortes histológicos foram analisados através de imagens digitalizadas obtidas em microscópio Olympus Triocular BX 40 acoplado à câmera Olympus Oly 200, ligada a um computador PC, através de placa digitalizadora Data Translation 3153.

Utilizando-se o software HL Image 97, determinou-se a porcentagem da imagem ocupada por ácinos, o número e o diâmetro médio dos ácinos e de seus núcleos, bem como calculou-se a proporção núcleo: citoplasma e a área celular numa amostra de 30 ácinos por animal. Também determinou-se a densidade de fibras colágenas por meio de segmentação por diferença de coloração (Thresholding image), criando-se uma imagem binária onde a região ocupada por fibras colágenas torna-se negra e o restante, branco. Determinando-se a porcentagem ocupada por negro nesta imagem, chega-se à densidade de fibras colágenas no processo de regeneração [1].
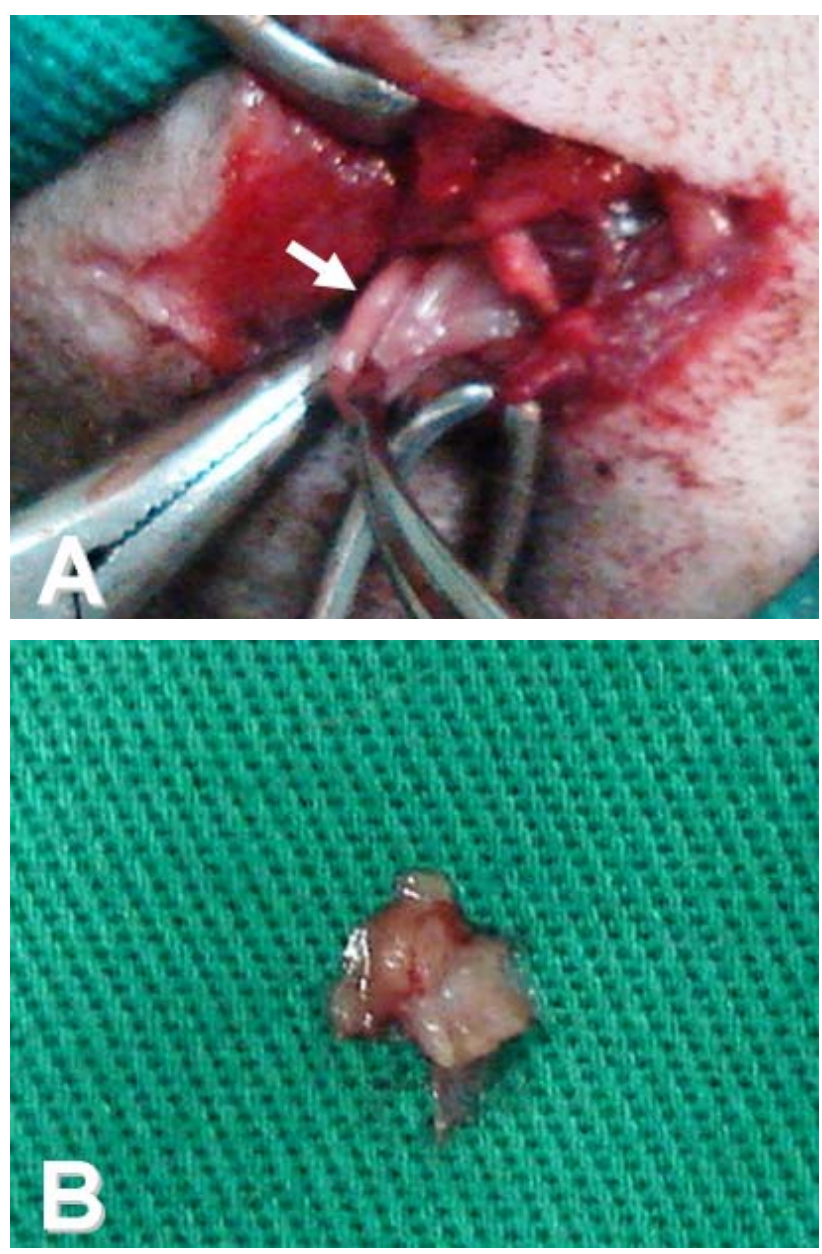

Figura 1. Exposição e remoção da glândula lacrimal principal de cão (A - seta). Nota-se a glândula parcialmente depois de removida $(\mathbf{B})$.
Para análise estatística, utilizou-se o Teste Kolmogorov-Smirnov associado ao Teste t e o Teste Wilcoxon, com significância de 5\%.

Foram respeitados todos os princípios éticos de utilização de animais em experimentos preconizados pelo Colégio Brasileiro de Experimentação Animal e pelo Comitê de Ética na utilização de animais da Universidade Federal de Uberlândia.

\section{RESULTADOS}

Durante os dois primeiros dias de PO, a pálpebra superior encontrava-se aparentemente edemaciada em $85,71 \%(n=6)$ dos animais e com discreta secreção de coloração amarelada. A partir do $3^{\circ}$ dia de PO, a pálpebra apresentou-se aparentemente normal e sem secreção.

Verificou-se diferenças significativas sobre a produção lacrimal entre as médias dos tratamentos $(\mathrm{p}=0,0033)$ do PE $(21,14 \mathrm{~mm} / \mathrm{min})$ aos $15 \mathrm{dias}$ $(17,86 \mathrm{~mm} / \mathrm{min})$, aos $30(19,57 \mathrm{~mm} / \mathrm{min})$ e $60 \mathrm{dias}$ $(21,57 \mathrm{~mm} / \mathrm{min}$ ) de PO (Figura 2). Os valores foram significativos comparando-se o momento de PE com 15 dias de PO e entre 15 e 60 dias de PO. Entre os momentos de PE e 30 dias de PO, PE e 60 dias de PO, 15 e 30 dias de PO e 30 e 60 dias de PO não houve diferença expressiva.

Notou-se diferença significativa na área dos núcleos dos ácinos ( $\mathrm{p}>0)$, na proporção núcleocitoplasma $(\mathrm{p}=0,0006)$ e área celular $(\mathrm{p}=0,0083)$ da glândula lacrimal entre o pré-operatório e 60 dias após remoção parcial da glândula lacrimal (Figura 3). Quanto à densidade de fibras colágenas ao longo do parênquima lacrimal, as diferenças não foram significativas entre o PE e após 60 dias de pós-operatório. Os valores encontram-se especificados na Tabela 1.

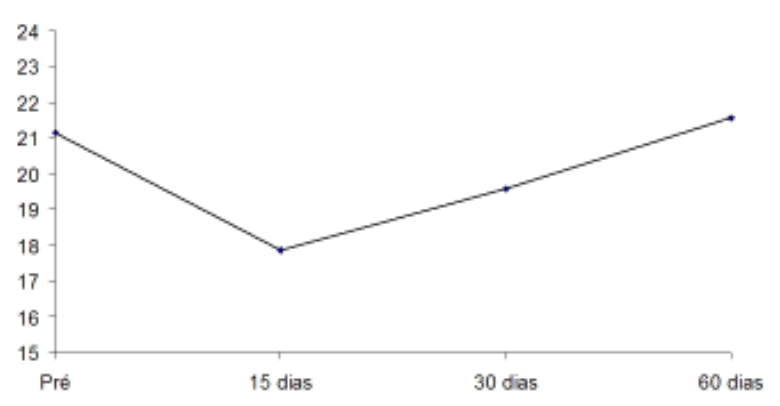

Figura 2. Médias da produção lacrimal ( $\mathrm{mm} / \mathrm{min})$ nos momentos de Pré-operatório e 15, 30 e 60 dias de pós-operatório da exérese de $50 \%$ do parênquima da glândula lacrimal principal de cães. Uberlândia, MG. 


\section{DISCUSSÃO}

Os valores normais do teste da lágrima de Schirmer em cães encontram-se entre $19,8 \mathrm{~mm} / \mathrm{min}$ $\pm 5,3 \mathrm{~mm} / \mathrm{min}[10]$. Neste experimento, apesar das diferenças significativas apresentadas entre o PE e
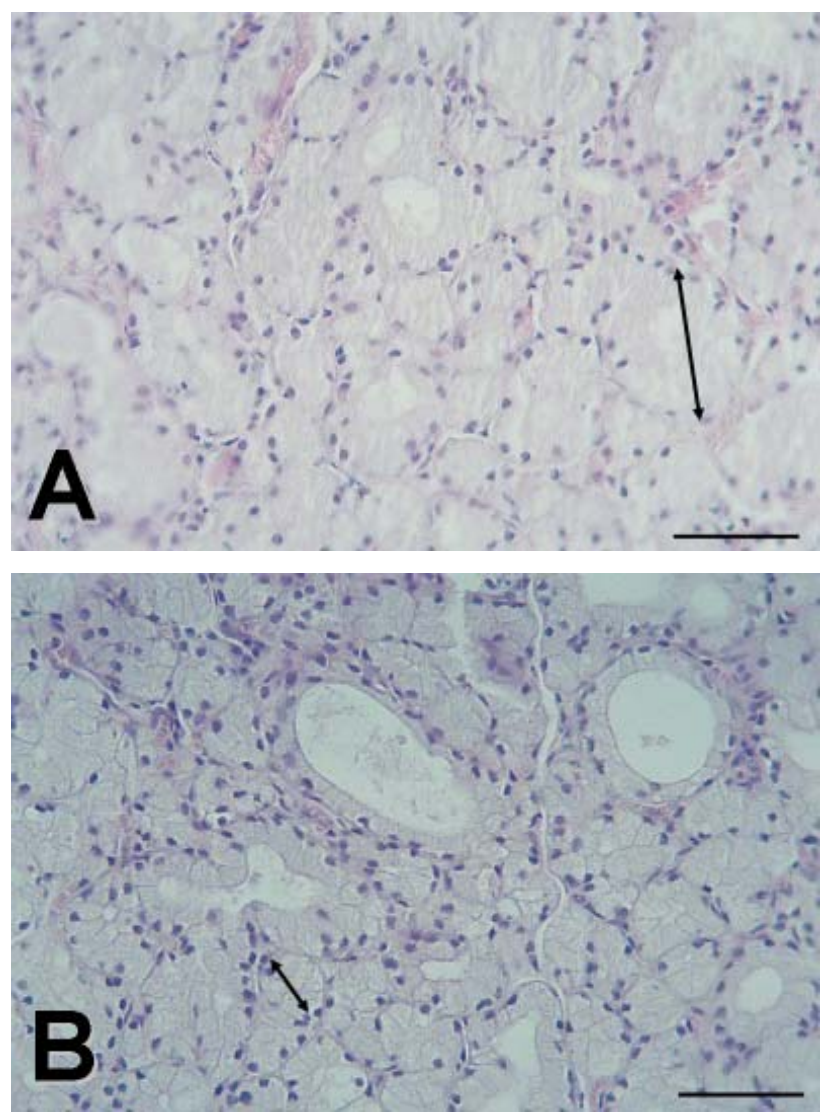

Figura 3. Fotomicrografia da glândula lacrimal no préoperatório (A) e após 60 dias da remoção da glândula lacrimal principal (B) em cão. Notar a diferença entre os ácinos de $\mathrm{A}$ e $\mathrm{B}$ em relação ao núcleo-citoplasma (setas). HE. Barra $=100 \mathrm{~mm}$.
15 dias e 15 e 60 dias de PO, os valores médios da produção lacrimal encontraram-se acima da normalidade durante todo o período de avaliação. O teste de Schirmer demonstrou que a média da produção lacrimal basal decresceu marcadamente após a cirurgia até $15^{\circ}$ dia de $\mathrm{PO}$ e, a partir de então, aumentou gradualmente no restante do período observado. Resultados conflitantes foram encontrados por outros autores que notaram decréscimo na produção até a $20^{\mathrm{a}}$ semana após remoção total da glândula lacrimal principal de macacos [8]. Em gatos, a remoção total da glândula lacrimal resultou em decréscimo dos valores do teste de Schirmer até 15 dias de observação [9], corroborando os resultados observados nos cães desta pesquisa. Tal divergência na literatura pode ser explicada pela diferença entre as espécies. Já em outro estudo com cães, contrariamente a este, os valores de produção lacrimal decresceram até o primeiro mês de avaliação [7]. No presente trabalho, a remoção parcial permitiu que a glândula lacrimal restante compensasse a produção aquosa do filme lacrimal.

Comparados aos valores observados no préoperatório, as áreas dos núcleos e a proporção núcleo-citoplasma foram significativamente maiores após 60 dias da remoção parcial da glândula lacrimal, enquanto as dimensões celulares foram significativamente menores (Figura 3). Esses dados sugerem aumento dos núcleos pelo acréscimo da atividade nuclear (transcrição) em resposta à demanda por secreção glandular e justificam os valores normais da produção lacrimal, avaliados sob o Teste de Schirmer, no $60^{\circ}$ dia de pós-operatório.

Tabela 1. Comparação das médias das áreas dos núcleos dos ácinos $\left(\mu m^{2}\right)$, da proporção citoplasma: núcleo, da área celular $\left(\mu \mathrm{m}^{2}\right)$ e da densidade de fibras colágenas $(\%)$ do parênquima lacrimal principal normal e após 60 dias de sua remoção parcial de cães sem raça definida. Uberlândia, MG.

\begin{tabular}{ccc}
\hline & PRÉ-OPERATÓRIO & APÓS 60 DIAS \\
\hline Área do núcleo $\left(\mathrm{um}^{2}\right)$ & $11,02 \pm 2,61^{\mathrm{a}}$ & $15,71 \pm 4,50^{\mathrm{b}}$ \\
Proporção núcleo: citoplasma & $0,08 \pm 0,01^{\mathrm{a}}$ & $0,12 \pm 0,02^{\mathrm{b}}$ \\
Área celular $\left(\mathrm{um}^{2}\right)$ & $146,52 \pm 47,41^{\mathrm{a}}$ & $131,82 \pm 64,74^{\mathrm{b}}$ \\
Fibras colágenas $(\%)$ & $0,043 \pm 0,013^{\mathrm{a}}$ & $0,046 \pm 0,007^{\mathrm{a}}$ \\
\hline
\end{tabular}

Média \pm desvio-padrão; $\mathrm{a}, \mathrm{b}$ - letras com sobrescritos iguais na mesma linha não diferem significativamente de acordo com o teste Kolmogorov-Smirnov e teste $\mathrm{t}$ $(\mathrm{p}<0,05)$. Salvo o parâmetro fibras colágenas, houve diferença significativa nos demais parâmetros mensurados. 
Após hipofisectomia parcial em ratos, autores encontraram alterações estruturais nas células secretoras como uma tentativa da função pituitária de adaptação à demanda do organismo, que podem ser designadas como regeneração funcional [11]. A demanda para maior excreção por células produtoras de secreções é acionada para responder ao reparo de uma injúria. Por meio de sinais químicos, o citoplasma dirige a demanda por síntese protéica requerida aos genes dentro do núcleo [6]. Na glândula lacrimal, esse complexo mecanismo de sinalização é utilizado por agonistas colinérgicos e adrenérgicos e outros fatores regulatórios para transmitir sinais associados com receptores de ligação dentro do citoplasma a fim de evocar liberação de produtos secretórios para o fluido lacrimal [4]. Neste experimento, com a remoção de parte da glândula, houve indução das células secretoras de lágrima à hiperatividade para compensar a demanda da produção. Portanto, estimulou ao aumento nuclear (núcleos gigantes e múltiplos em constante transcrição-síntese protéica) e citoplasmas pequenos com pouco armazenamento de lágrima. Tal fato esclarece o aumento celular aos 60 dias, a queda da produção lacrimal após 24 horas e o retorno da produção lacrimal dentro dos parâmetros normais aos 60 dias de PO.

A destruição do tecido conjuntivo por infecção ou trauma é seguida por um grande número de alterações nos tecidos adjacentes que são, a princípio, de natureza protetora e, posteriormente, reparadora. Uma vez protegido, ou cessado a reação infla- matória, os fibroblastos secretam matriz do tecido conjuntivo e as células endoteliais dos capilares formam novo leito capilar na margem da ferida. Posteriormente, o número de fibroblastos diminui e os que permanecem tornam-se fibrócitos [12]. Neste experimento, a densidade de fibras colágenas encontradas ao longo do parênquima lacrimal entre o PE e após 60 dias de pós-operatório possivelmente não foi significativa devido à deposição de fibras ser direcionada para o local da incisão e a reação inflamatória, juntamente com a deposição de fibras colágenas ter cessado com 60 dias de PO.

\section{CONCLUSÃO}

A exérese parcial do parênquima da glândula lacrimal principal em cães não interfere significativamente na queda da produção lacrimal até o $60^{\circ}$ dia de avaliação, com retorno da produção dentro dos padrões normais.

\section{NOTAS INFORMATIVAS}

${ }^{1}$ Schirmer Tear Test, Schering-Plough Union, New Jersey, EUA.

${ }^{2}$ Quinotril, Instituto Valle, Montes Claros, MG, Brasil.

${ }^{3}$ Tramal, União Química Farmacêutica Nacional, Pouso Alegre, MG, Brasil.

${ }^{4}$ Ketojet, União Química Farmacêutica Nacional, Guaçu, SP, Brasil.

${ }^{5}$ Acepran, Univet, São Paulo, SP, Brasil.

${ }^{6}$ Cetamin, Syntec, Patrocínio Paulista, SP, Brasil.

${ }^{7}$ Kensol, Kong, Santana de Parnaíba, SP, Brasil.

${ }^{8}$ Riodine, Rioquímica Indústria Farmacêutica, São José do Rio Preto, SP, Brasil.

\section{REFERÊNCIAS}

1 Alvarenga B.O., Beletti M.E., Fernandes E.A., Silva M.M., Campos L.F.B. \& Ramos S.P. 2004. Efeitos de fontes alternativas de fósforo nas rações de engorda e abate sobre a morfologia intestinal de frangos de corte. Bioscience Journal. 20(3): 5559.

2 Cheng S., Kuchiiwa S., Kuchiiwa T. \& Nakagawa S. 2000. Three novel neural pathways to the lacrimal glands of the cat: an investigation with cholera toxin B subunit as a retrogade tracer. Brain Research. 873(1): 160-164.

3 Chiapetto D.J.P. 2006. Emergencias en oftalmología. Disponível em http://www.medvet.com.ar. Acessado em 07/2008.

4 Dart D.A. 2004. Interaction of EGF family growth factors and neurotransmitters and the EGF family of growth factors. Experimental Eye Research. 78(3): 337-345.

5 Diemsem C. 1986. Órgãos da visão. In: Getty R. (Ed). Sisson/Grossman anatomia dos animais domésticos. 5.ed. Rio de Janeiro: Guanabara Koogan, pp. 1635-1652.

6 Ham A.W. 1974. Microscopy and biology of interphase nuclei of functioning specialized cells. In: Histology. 7th edn. Phyladelphia: J.B. Linppincott Company, pp. 2-20.

7 Helper L.C. 1970. The effect of lacrimal gland removal on the conjunctiva and cornea of the dog. Journal of the American Veterinary Medical Association. 157(1): 72-75. 
8 Maitchouk D.Y., Beuerman R.W., Ohta T., Stern M. \& Varnell R.J. 2000. Tear production after unilateral removal of the main lacrimal gland in squirrel monkeys. Archives of Ophthalmology. 118(2): 246-252.

9 Mclaughlin S.A., Brightman A.H., Lloyd C.H., Primm N.D., Brown M.G. \& Greeley S. 1988. Effect of removal of lacrimal and third eyelid glands on Schirmer tear test results in cats. Journal of the American Veterinary Medical Association. 193(7): 820-822.

10 Osler W. 2005. Técnicas básicas de diagnóstico. In: Slatter D. (Ed). Fundamentos de oftalmologia veterinária. 3.ed. São Paulo: Roca, pp. 97-134.

11 Saeger W. \& Warnecke H. 1980. Ultrastructural examination of the regeneration of the rat adenohypophysis after partial hypophysectomy. Virchows Archives. 387(3): 279-288.

12 Snell R.S. 1985. Tecido conjuntivo. In: Histologia clínica. Rio de Janeiro: Interamericana, pp. 87-126.

13 Stern M.E., Gao J., Siemasko K.F., Beuerman R.W. \& Pflugfelder S.C. 2004. The role of lacrimal functional unit in the pathophysiology of dry eye. Experimental Eye Research. 78(3): 409-416.

14 Zoukhri D. 2006. Effect of inflammation on lacrimal gland function. Experimental Eye Research. 82(5): 885-898. 